\title{
The selective sequestration of glucosinolates by the cabbage aphid severely impacts a predatory lacewing
}

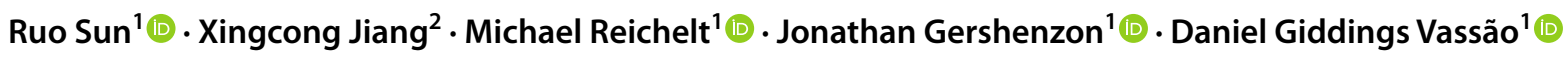

Received: 17 August 2020 / Revised: 10 December 2020 / Accepted: 11 December 2020 / Published online: 29 December 2020

(c) The Author(s) 2020

\begin{abstract}
The cabbage aphid Brevicoryne brassicae is a notorious agricultural pest that specializes on plants of the Brassicaceae family, which are chemically defended by glucosinolates. By sequestering glucosinolates from its host plants and producing its own activating enzyme (myrosinase), this aphid employs a self-defense system against enemies paralleling that in plants. However, we know little about the metabolic fate of individual glucosinolates during aphid sequestration and activation and about the biochemical effects of this defense on aphid enemies. Here, we probed these questions focusing on $B$. brassicae and a predatory lacewing, Chrysoperla carnea. We found that distinct glucosinolates were accumulated by B. brassicae at different rates, with aliphatic glucosinolates being taken up more quickly than indolic ones. B. brassicae myrosinase enzymatic activities toward different glucosinolates were strongly correlated to their rates of accumulation in vivo. Surprisingly, after simulated predation, the production of toxic isothiocyanate products (ITCs) was quantitatively outweighed by less toxic products such as nitriles and ITC-conjugates. Nevertheless, the defensive cocktails significantly impaired $C$. carnea development. Tissue-specific quantification of glucosinolate metabolites revealed that the lacewings employ both conjugation and mobilization to reduce the toxicity of aliphatic ITCs, but these strategies were only partially effective. These results clarify the metabolic fates of glucosinolates after sequestration by an aphid herbivore and further in a higher trophic level, as well as the consequences for predator survival and development, and might be instructive for integrative pest management approaches targeting the cabbage aphid.
\end{abstract}

Keywords Brevicoryne brassicae · Detoxification · Insect chemical defense · Isothiocyanates · Multi-trophic interaction · Plant chemical defense

\section{Key message}

Communicated by Blas Lavandero.

Ruo Sun and Xingcong Jiang have contributed equally

Supplementary Information The online version contains supplementary material available at (https://doi.org/10.1007/ s10340-020-01319-2)

Daniel Giddings Vassão

vassao@ice.mpg.de

1 Department of Biochemistry, Max Planck Institute for Chemical Ecology, 07745 Jena, Germany

2 Department of Evolutionary Neuroethology, Max Planck Institute for Chemical Ecology, 07745 Jena, Germany
- The cabbage aphid selectively accumulates and activates glucosinolates, affecting higher trophic level enemies.

- Glucosinolates with varying side chains are accumulated at different rates, and uptake selectivity matches the enzymatic activity of the insect myrosinase.

- The toxic aphid-derived aliphatic isothiocyanates overwhelm the detoxification capacity of a lacewing predator, impairing its development.

- High foliar aliphatic glucosinolate concentrations might interfere with the use of lacewings for cabbage aphid control. 


\section{Introduction}

Plants of the order Brassicales, such as those in the Brassicaceae and Capparaceae families, produce glucosinolates and myrosinases as an effective two-component defensive system against non-adapted herbivores and pathogens. In spite of these defenses, the yields of glucosinolate-containing crop plants are greatly affected by pests. Glucosinolates are glucosylated pro-toxins that are constitutively and abundantly accumulated in sulfur-rich S-cells (Koroleva and Cramer 2011), whereas the activating enyzmes, myrosinases ( $\beta$-thioglucoside glucohydrolases), are present in protein-enriched idioblasts called myrosin cells (Andréasson and Jørgensen 2003; Rask et al. 2000; Wittstock and Gershenzon 2002). Such a physical compartmentation avoids the self-intoxication that could result from the unintended hydrolysis of glucosinolates by myrosinases, so that mixing of hydrolytic activating enzymes and their glucosinolate substrates occurs only upon tissue damage, e.g., during attack by a herbivore. The aglucones thus produced are unstable and rearrange to form an array of downstream metabolites including isothiocyanates (ITCs), simple nitriles (CNs), thiocyanates, and epithionitriles. The outcome of hydrolysis is dependent on the glucosinolate side chains, the presence of protein modulators (specifier proteins), as well as reaction conditions and the presence of metal ions and other cofactors (Eisenschmidt-Bönn et al. 2019). Among the products of glucosinolate hydrolysis, the chemically reactive ITCs (containing an $-\mathrm{N}=\mathrm{C}=\mathrm{S}$ functional group) play major roles in plant-herbivore interactions. Other hydrolysis products, such as CNs, are thought to be less toxic than ITCs and can have a role in indirect defense (Burow et al. 2006).

Glucosinolates are amino acid-derived, glucosylated specialized metabolites (Blažević et al. 2020). The basic structure of glucosinolates comprises three building blocks: a $\beta$-thioglucose moiety, a sulfonated oxime moiety, and a structurally diverse side chain that allows the characterization of glucosinolates into three major categories, namely aliphatic, indolic, and benzenic glucosinolates (Agerbirk and Olsen 2012). In general, the toxicity of glucosinolate-derived ITCs is conferred by the electrophilic $-\mathrm{N}=\mathrm{C}=\mathrm{S}$ functional group that reacts with intracellular nucleophiles (Hanschen et al. 2012; Jeschke et al. 2016). However, the side chain structure can affect the toxicity too. ITC side chains help dictate post-hydrolysis reactivities, and toxicity is altered for example by a rapid loss of the $-\mathrm{N}=\mathrm{C}=\mathrm{S}$ group (e.g., to form the carbinol products of indolic glucosinolates) (Wittstock et al. 2016). Additionally, the lipophilicity of the side chain can facilitate the diffusion of ITCs through the cellular lipid bilayer membranes to reach the intracellular environment. While electron-withdrawing groups on the side chain can increase overall electrophilicity and reactivity, electrostatic attraction or steric hindrance between the side chain and target proteins will also promote selective reactivity (Brown et al. 2011). Hence, in addition to the unique properties of the electrophilic $-\mathrm{N}=\mathrm{C}=\mathrm{S}$ functional group, the structural diversity of various types of ITC side chains expands their potency to a broader range of targets.

The cabbage aphid Brevicoryne brassicae (L.) (Hemiptera: Aphididae) is a piercing-sucking herbivore, and as such can avoid the glucosinolate-myrosinase defense system by minimizing tissue damage (Louis et al. 2012). This insect is a pest of crop plants from the family Brassicaceae worldwide, stunting plant growth and transmitting at least 20 viruses (Kessing and Mau 1991). This insect completes an average of 15 generations per year, causing yield losses of up to $85 \%$ (Gabrys 2008; Mpumi et al. 2020). B. brassicae has been found to accumulate glucosinolates from host plants (Kos et al. 2011). However, how distinct glucosinolates are dynamically accumulated has not been clarified. In addition to sequestering certain ingested glucosinolates in its hemolymph, $B$. brassicae produces its own endogenous myrosinase (BMY, B. brassicae $\beta$-thioglucoside glucohydrolase) in its head and thoracic muscles (Kazana et al. 2007). The extent to which endogenous BMY selectively acts on the glucosinolates actually sequestered by the insect is yet unknown. As in the plant, once insect tissues are disrupted by predators, sequestered glucosinolates and BMY meet resulting in the formation of toxic ITCs, giving $B$. brassicae the moniker "walking mustard oil bomb" (Kazana et al. 2007). However, the factors influencing glucosinolate hydrolysis in B. brassicae are not fully understood despite their ecological importance.

The glucosinolates sequestered by $B$. brassicae and their resulting activation products may move up the food chain and cause further negative effects on higher trophic levels (Kazana et al. 2007; Kos et al. 2011). As an important biocontrol organism, the common green lacewing Chrysoperla carnea has received increasing research attention for its ability to handle prey like aphids and soft caterpillars. It has recently been shown that $C$. carnea larvae can tolerate dietary 4-methylsulfinylbutyl glucosinolate (4MSOBGSL), by detoxifying the hydrolysis product 4MSOB-ITC via the general mercapturic acid pathway, and storing some of these compounds into its anal defensive secretion. In spite of 4MSOB-ITC slightly delaying larval development, this compound had no impact on pupal mortality and adult egglaying capacity (Sun et al. 2019). However, the content of toxic glucosinolate metabolites produced by $B$. brassicae differs markedly from that in the Plutella xylostella larvae used in that previous study. Thus, the physiological and metabolic responses of $C$. carnea to preying on $B$. brassicae 
remain unknown and cannot be directly inferred from those previous results.

Here, we examine in detail the metabolism of glucosinolates in this aphid-lacewing interaction and its ecological effects. First, we quantified the accumulation of Arabidopsis thaliana glucosinolates by B. brassicae over time. Second, we characterized the catalytic specificity of aphid BMY toward a repertoire of $A$. thaliana glucosinolates. Third, we determined the activation products of the sequestered glucosinolates in B. brassicae in response to a predationlike mechanical stimulus. Subsequently, we measured the physiological impact caused by toxic glucosinolate metabolites produced by $B$. brassicae on the predatory lacewing $C$. carnea. Together, this study advances our understanding of how the cabbage aphid successfully co-opts a plant defense, and the fate of a predatory lacewing that encounters these defenses in its prey.

\section{Materials and methods}

\section{Plants and insects}

Arabidopsis thaliana land race Columbia-0 (Col-0) accession wild-type plants (with wild-type glucosinolates), transgenic myb28myb29 knockout mutant plants (without aliphatic glucosinolates) (Sønderby et al. 2007), and myb$28 m y b 29$ cyp 79b2cyp79b3 knockout mutant plants (without any glucosinolates) (Mikkelsen et al. 2003) were used for experiments. Brussels sprouts plants (Brassica oleraceae var. gemmifera) were used for rearing of insect cultures. Plants were grown in climate-controlled short-day environmental chambers at $21{ }^{\circ} \mathrm{C}, 60 \%$ relative humidity, and a 14:10 h light:dark photoperiod. Brevicoryne brassicae colonies, generously provided by Dr. Rieta Gols (Wageningen University \& Research, Wageningen, Netherlands), were fed on Brussels sprouts plants and maintained in a climate-controlled long-day environmental chamber at $21{ }^{\circ} \mathrm{C}$, $60 \%$ relative humidity, and a 16:8 h light:dark photoperiod. Chrysoperla carnea eggs were purchased from Katz Biotech AG (Baruth, Germany) and were used for experiments. Newly hatched $C$. carnea larvae were fed on separate $B$. brassicae populations feeding on either $A$. thaliana wildtype or myb28myb29 plants in the same controlled long-day environmental chamber. Experiments were conducted in a similarly controlled long-day environmental chamber.

\section{Sequestration of glucosinolates from host plants by $B$. brassicae}

To measure the accumulation of various host plant glucosinolates in B. brassicae aphids, we analyzed the glucosinolate content of $B$. brassicae and plants of their host
A. thaliana Col-0, at the time points of $1 \mathrm{~h}, 3 \mathrm{~h}, 6 \mathrm{~h}, 9 \mathrm{~h}$, 1 day, 2 days, 3 days, 4 days, and 6 days post-infestation. First, we purged the glucosinolate content of $B$. brassicae by rearing aphids on A. thaliana myb28myb29cyp $79 b$ 2 cyp $79 b 3$ plants over 10 days. Then, we transferred 40 adult aphids to each $A$. thaliana wild-type plant, with 56 plants being infested in total. At each time point, 10 adult aphids were collected from each of four randomly selected plants, with aphids from each plant being pooled into a $1.5 \mathrm{~mL}$ Eppendorf tube as one sample (i.e., four independent replicates per time point, with nine time points in total). Leaves from these plants were sampled and collected in $5 \mathrm{~mL}$ tubes, and the used plants were then discarded and not used for later time points. Additionally, on day 6 , we also collected second- and fourth-instar nymphs (15 nymphs pooled per sample, $n=4$ replicates), as the offspring of the adults initially transferred. Samples were immediately frozen in liquid nitrogen. Leaf material was ground using a tissue-grinding pestle. The samples were kept under $-80{ }^{\circ} \mathrm{C}$ and then weighed (FW, fresh weight) before metabolite extraction and detection as described in the supplementary materials.

\section{Myrosinase assay with $A$. thaliana wild-type glucosinolates}

To measure the glucosinolate substrate preference of recombinant BMY and a protein extract of B. brassicae fourthinstar nymphs, enzyme activities were determined with extracted $A$. thaliana glucosinolates. Soluble protein of $B$. brassicae fed on A. thaliana myb28myb29cyp79b2cyp $79 b 3$ plants was extracted by homogenizing in citric acid buffer (50 mM, and 10\% glycerol; pH 4.1). Recombinant BMY protein produced in Escherichia coli cells was purified as described in the supplementary materials. Protein concentration was measured using the Bradford reagent (Serva Electrophoresis). A $2 \mu \mathrm{g}$ quantity of protein from each sample in $100 \mu \mathrm{L}$ citric acid buffer $(50 \mathrm{mM}, \mathrm{pH} 4.1)$ was reacted with $10 \mu \mathrm{L}$ crude glucosinolate extract from A. thaliana wild-type plants (described in the supplementary materials) at $28{ }^{\circ} \mathrm{C}$. Aliquots containing $10 \mu \mathrm{L}$ of the reaction solution were taken out at $0 \mathrm{~min}, 5 \mathrm{~min}, 10 \mathrm{~min}, 15 \mathrm{~min}$, $30 \mathrm{~min}$, and $60 \mathrm{~min}$ reaction time points and added to 90 $\mu \mathrm{L}$ pure methanol to immediately stop the reaction. Meanwhile, denatured $B$. brassicae protein extracts, which had been heated at $100{ }^{\circ} \mathrm{C}$ for $1 \mathrm{~h}$, and protein of empty vectortransformed E. coli cells were processed as controls to look for non-enzymatic and non-BMY degradation of glucosinolates. Subsequently, the concentration of remaining intact glucosinolates was determined by LC-MS/MS (described in the supplementary materials) to calculate the percentage of glucosinolate hydrolysis. 


\section{Myrosinase assay with pure glucosinolates}

To determine the substrate specificity of recombinant BMY toward pure glucosinolates, $1 \mu \mathrm{g}$ of purified recombinant BMY was individually incubated with $2 \mathrm{mM}$ final concentrations of glucosinolates in citric acid buffer $(50 \mu \mathrm{L}, 50 \mathrm{mM}$, $\mathrm{pH} 4.1$ ) for $60 \mathrm{~min}$ at $28^{\circ} \mathrm{C}$. The reactions were terminated by boiling for $2 \mathrm{~min}$ at $100{ }^{\circ} \mathrm{C}$, and the formation of glucose removed from glucosinolates was determined by the glucose oxidase procedure using the Glucose Assay Kit (Sigma, St. Louis, Missouri, USA) according to the manufacturer's instructions. The absorbance of colored products used for glucose concentration quantification was measured at $540 \mathrm{~nm}$ using an Infinite M200 Luminescence Microplate Reader (Tecan, Männedorf, Switzerland). Glucosinolates used for assays are listed in Table S2.

\section{Kinetic characterization of BMY}

Enzyme assays were conducted to measure recombinant BMY activity with different concentrations of glucosinolates. A $0.3 \mu \mathrm{g}$ amount of purified recombinant BMY protein $(53.74 \mathrm{kDa})$ was reacted with $1 \mu \mathrm{M}$ to $1500 \mu \mathrm{M}$ of each glucosinolate in citric acid buffer $(50 \mu \mathrm{L}, 50 \mathrm{mM}$, pH 4.1) for $10 \mathrm{~min}$ at $28{ }^{\circ} \mathrm{C}$. The reaction was terminated by adding $450 \mu \mathrm{L}$ of pure ice-cold methanol. The concentration of remaining glucosinolates was measured by LC-MS/ MS to calculate the percentage of hydrolyzed glucosinolates.

\section{Glucosinolate-derived metabolites in B. brassicae damaged tissues}

To detect the formation of glucosinolate-derived metabolites in vivo, B. brassicae fourth-instar nymphs were attacked with a brush until a small amount of hemolymph was visible on the body surface, to mimic damage caused by an enemy attack. Forty aphids on each of $5 \mathrm{~A}$. thaliana wild-type plants were injured and allowed to continue feeding on the host plants. At the time points of $0 \mathrm{~min}, 5 \mathrm{~min}$, and $20 \mathrm{~min}$ post tissue damage, 10 surviving aphids from each plant were pooled into a $1.5 \mathrm{~mL}$ Eppendorf tube as one sample. Samples were immediately frozen in liquid nitrogen. Metabolite extraction and the measurement of glucosinolate-derived metabolites are described in the supplementary materials.

\section{Conversion of glucosinolate to simple nitrile in the presence of Fe (II)}

To determine the correlation of the Fe (II) concentration with simple nitrile $(\mathrm{CN})$ formation during glucosinolate hydrolysis catalyzed by $B$. brassicae myrosinase, 4MSOBGSL was hydrolyzed by recombinant BMY or extracted $B$. brassicae proteins in the presence of different concentrations of Fe (II). A $2 \mu \mathrm{g}$ portion of purified recombinant BMY or proteins extracted from $B$. brassicae fourth-instar nymphs were assayed with $1 \mathrm{mM} 4 \mathrm{MSOB}-\mathrm{GSL}$ in citric acid buffer (100 $\mu \mathrm{L}, 50 \mathrm{mM}$, pH 4.1) with EDTA (50 mM, conjugation agent to deplete endogenous $\mathrm{Fe}(\mathrm{II})$ ); or $0 \mathrm{mM}, 0.01 \mathrm{mM}$, $0.05 \mathrm{mM}, 0.1 \mathrm{mM}$, or $0.5 \mathrm{mM}\left(\mathrm{NH}_{4}\right)_{2} \mathrm{Fe}\left(\mathrm{SO}_{4}\right)_{2}$ at $28{ }^{\circ} \mathrm{C}$ for $30 \mathrm{~min}$. The reaction was stopped by adding $400 \mu \mathrm{L}$ of pure methanol. As a negative control, the proteins were incubated in $100 \mu \mathrm{L}$ of citric acid buffer without a glucosinolate substrate under the same conditions. Subsequently, the formation of products from 4MSOB-GSL was measured by LC-MS/MS as described in the supplementary materials.

\section{C. carnea larval development, pupation, and adult weights}

To determine how the glucosinolate accumulation in $B$. brassicae physiologically impacts its predator $C$. carnea, larvae of $C$. carnea were continuously given $B$. brassicae fed on either A. thaliana wild-type or myb28myb29 plants since hatching. Each $C$. carnea larva was kept in a $35 \mathrm{~mL}$ transparent plastic vial with sufficient prey according to the developmental stage of the predator, with additional prey added twice daily to ensure ad libitum feeding. The larval development time, larval mortality, pupation percentage, and adult emergence of $C$. carnea were recorded. The weights of 30 C. carnea larvae from each group were determined at 5, $7,9,11,13,15$, and 17 days post-hatching. Meanwhile, the percentage of larval mortality for a cohort of $60 \mathrm{C}$. carnea larvae was recorded during 7-21 days post-hatching, and the percentage of larval pupation in each group was recorded during 13-25 days post-hatching. Moreover, the numbers of adults emerged (from 30 pupae) in each group were recorded during 11-17 days post-pupation, and the percentages of emergence and the duration until emergence were calculated. The adults were sexed and weighed.

\section{Glucosinolate-derived metabolites in C. carnea}

C. carnea preying on B. brassicae fed on A. thaliana wildtype plants were collected for metabolite analyses. Thirdinstar $C$. carnea larvae were collected (one larva as one sample). The anal secretions of $C$. carnea larvae (from three larvae pooled as one sample) were collected with a $10 \mu \mathrm{L}$ pipette. Larvae transferred the secretion droplet to the pipette tip as a defense reaction when touched by the tip on their dorsal abdomen. Collected anal secretions were washed in extraction solvent $(200 \mu \mathrm{L}, 60 \%$ methanol in water, pH 3.0) immediately and kept under $-20{ }^{\circ} \mathrm{C}$ until further analysis. Pupal pellets left in the cocoons (from three cocoons pooled as one sample) were collected after adult emergence. The meconium excreted by the adults (from three adults pooled as one sample) in the first few hours after 
emergence was collected simultaneously with adults (one adult as one sample). All collected tissues (five replicates for each) were immediately frozen in liquid nitrogen and stored under $-80{ }^{\circ} \mathrm{C}$ until further analysis. The weighed tissues were homogenized in extraction solvent $(200 \mu \mathrm{L}, 60 \%$ methanol in water, $\mathrm{pH}$ 3.0) with ceramic beads. Samples were centrifuged to separate undissolved particles. Clear supernatants were analyzed by LC-MS/MS as described in the supplementary materials to detect the concentration of 4MSOB-GSL and its metabolites.

\section{Statistical analyses}

Data were analyzed using R v.3.6.1, including the "agricolae," "car," and "survival" packages. Figures were created using Origin 2019 and Adobe Illustrator CS5. Significant differences between means $( \pm$ s.e.) of metabolites and enzyme assay results were determined by Tukey HSD tests in combination with one-way/two-way ANOVA. Significance of $C$. carnea weight differences between medians was determined by two-tailed Mann-Whitney $U$ Test. C. carnea larval mortality, larval pupation, and adult emergence were analyzed by Kaplan-Meier survival tests. Data analyzed by ANOVA were checked for statistical prerequisites such as homogeneity of variances and normality.

\section{Results}

\section{B. brassicae accumulates glucosinolates at different rates}

The cabbage aphid $B$. brassicae sequesters certain glucosinolates from its cruciferous host plants, but the relative rates of accumulation of individual glucosinolates have not been studied. In order to measure the uptake of those compounds, glucosinolate-free aphid adults were first generated by rearing on glucosinolate-deficient mutant plants, and then transferred to $A$. thaliana Col-0 wild-type plants. The glucosinolates accumulated by the aphids were then quantified at selected time points during a 6-day experiment (Fig. S1). The contents of glucosinolates sequestered by the aphids were further compared with the content of the host plant. Overall, the relative accumulation rates revealed that sequestration of aliphatic glucosinolates occurred more rapidly than that of indolic glucosinolates: the concentrations of aliphatic glucosinolates in B. brassicae exceeded those in A. thaliana within one day, while at least 2 days were required for indolic glucosinolates to reach the same concentrations as in the host plant (Fig. 1a). Interestingly, the four aliphatic glucosinolates with a methylsulfinyl group (with a $\mathrm{MeS}=\mathrm{O}$ functional group on the side chain) had different accumulation rates; the glucosinolate with the longest side chain, 8-methylsulfinyloctyl glucosinolate (8MSOO-GSL), was remarkably more efficiently accumulated (Fig. 1b). Quantitatively, the most highly concentrated glucosinolates accumulated by day 6 were the three aliphatic glucosinolates 4MSOB-GSL, 8MSOO-GSL, and 4MTB-GSL (4-methylthiobutyl glucosinolate), respectively (Fig. 1c, dark-orange bars). Of note, 4MSOB-GSL, which dominates the total foliar glucosinolate pool of $A$. thaliana wild-type Col-0 plants (around 55\%), was also highly accumulated in B. brassicae. Although the indolic glucosinolate I3M-GSL (indolyl-3-methyl glucosinolate) also accumulated by day 6 , its concentration was much lower than that of its aliphatic counterparts. The two other indolic glucosinolates remained at very low levels (Fig. 1c). Glucosinolate accumulation was also quantified in second- and fourth-instar $B$. brassicae nymphs, with concentrations found to be similar to those in the adult insects (Fig. 1c). Taken together, these results show that different glucosinolates are accumulated at different rates during all life stages of the aphid, and the length of the side chains determines the selective accumulation of aliphatic glucosinolates.

\section{The catalytic activity of B. brassicae BMY correlates with glucosinolate sequestration patterns}

Given that aliphatic glucosinolates were selectively more highly accumulated, we sought to determine if this is reflected in the activity of the endogenous aphid myrosinase BMY. In a first step, we quantified the transcript level of the BMY-encoding gene bmy in aphids when feeding on wild-type $A$. thaliana plants. We found that bmy was constitutively expressed in both nymph and adult stages (Fig. S2a). Moreover, we did not detect any significant alterations in bmy expression induced by feeding on three genotypes of host plants differing in glucosinolate content, as exemplified by testing fourth-instar nymphs (Fig. S2b). Furthermore, the myrosinase activities in crude aphid protein extracts toward two substrates (the aliphatic glucosinolate 4MSOBGSL and the indolic glucosinolate I3M-GSL) were similar among aphid life stages and after feeding on plants differing in glucosinolate contents (Fig. S2c-f). These results suggest that bmy is constitutively expressed in $B$. brassicae, and that BMY activity is independent of aphid development and host glucosinolate content.

Next, we sought to examine the catalytic activity of BMY toward the mixture of glucosinolates in A. thaliana wildtype Col-0 plants. We therefore heterologously expressed bmy in E. coli and affinity-purified the recombinant BMY protein (Fig. S3). When mixed with a plant glucosinolate extract, BMY had higher activity toward aliphatic glucosinolates than indolic glucosinolates (Fig. 2a), in agreement with a parallel test using a crude protein extract from fourthinstar B. brassicae (Fig. 2b). BMY hydrolyzed $74 \%-91 \%$ of 
(a)

\section{Accumulation dynamic pattern}

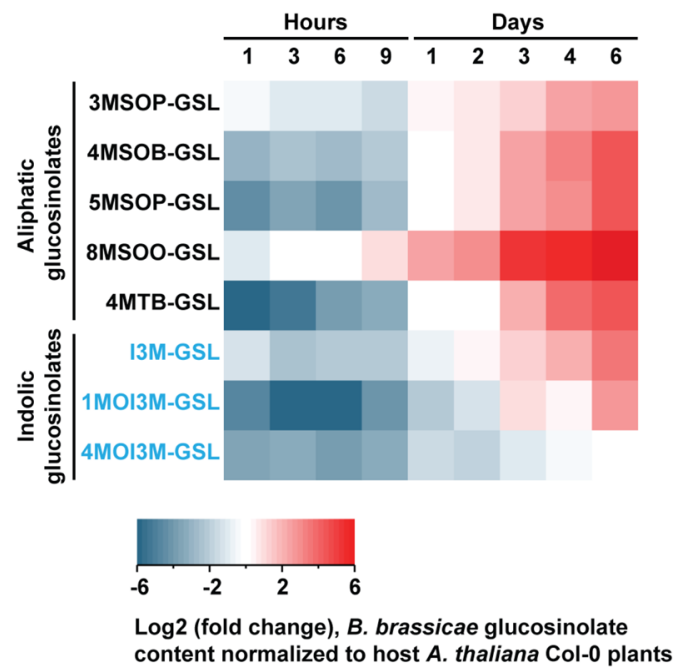

(b)

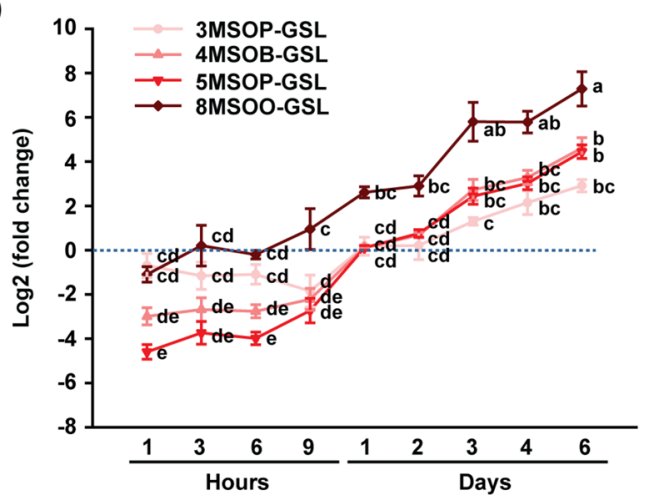

Fig. 1 Dynamic accumulation of distinct glucosinolates in the cabbage aphid $B$. brassicae. a A heatmap shows the dynamic patterns of the sequestration of host plant glucosinolates in $B$. brassicae adults fed with $A$. thaliana wild-type Col-0 plants, highlighting the preference for glucosinolates with different side chains. The colors represent the $\log 2$ (fold change) of the content of each accumulated glucosinolate in the body of $B$. brassicae relative to those of the host plants measured at each time point post-aphid infestation. The actual glucosinolate concentrations in both $B$. brassicae and the host plants are shown in Fig. S1. b The relative accumulation of individual aliphatic glucosinolates containing methylsulfinyl groups in their side chains occurred at differential rates, roughly increasing with side chain length (time: $F_{8,108}=123.7, P \leq 0.001$; metabolites: $F_{3,108}=$ 75.30, $P \leq 0.001$; time $\times$ metabolites: $F_{24.108}=3.37, P \leq 0.001 ; n=4$

aliphatic glucosinolates within $60 \mathrm{~min}$, but only up to $62 \%$ of indolic glucosinolates (Fig. 2b). Irrespective of its native or recombinant form, BMY did not appear to use the indolic glucosinolate 4MOI3M-GSL as a substrate (Fig. 2a,b). We additionally quantified the glucose released during hydrolysis of 10 selected pure glucosinolates (Fig. 2c). Consistent with the results above, BMY had highest activities toward pure aliphatic glucosinolates than toward benzenic or indolic glucosinolates (Fig. 2c). Among the tested
Accumulation quantity Day 6

Glucosinolate content (nmol/g, FW)<smiles>O=S(=O)(O)/N=C(/I)SCl</smiles>
2000300040005000100001500020000

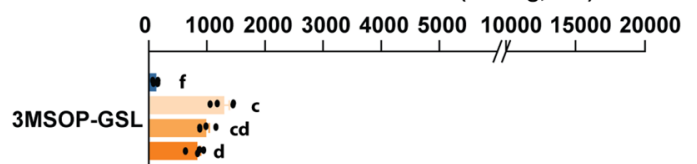
3MSOP-GSL $\ddot{00} \mathrm{~cd}$<smiles>CCCCCCCC</smiles><smiles>CCCCCC(C)=O</smiles>

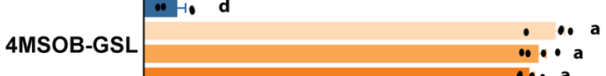<smiles>CCCCCCCCCC</smiles><smiles>CCCCCCC[Hg]C</smiles>

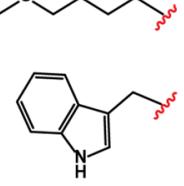<smiles>CCCc1cn(C)c2ccccc12</smiles>
$\mathrm{H}_{3} \mathrm{Co}$<smiles>CCc1c[nH]c2cccc(OC)c12</smiles>
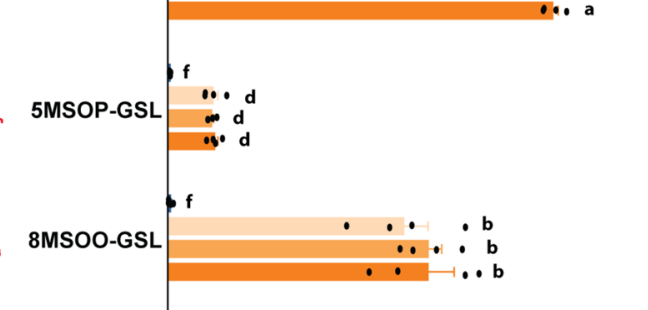

4MTB-GSL
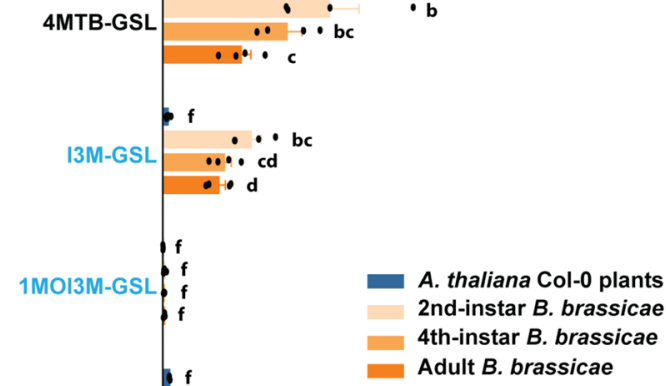

in all points). c The patterns of accumulation of aliphatic glucosinolates in $B$. brassicae did not differ among developmental stages. Accumulation quantity was tested at day 6 post-infestation (organisms: $F_{3,96}=247.2, P \leq 0.001$; metabolites: $F_{796}=708.2, P \leq 0.001$; organisms $\times$ metabolites: $F_{21,96}=72.85, P \leq 0.001 ; n=4$ in all bars). 3MSOP-GSL, 3-methylsulfinylpropyl glucosinolate; 4MSOB-GSL, 4-methylsulfinylbutyl glucosinolate; 5MSOP-GSL, 5-methylsulfinylpentyl glucosinolate; 8MSOO-GSL, 8-methylsulfinyloctyl glucosinolate; 4MTB-GSL, 4-methylthiobutyl glucosinolate; I3M-GSL, indolyl-3-methyl glucosinolate; 1MOI3M-GSL, 1-methoxyindol3-ylmethyl glucosinolate; 4MOI3M-GSL, 4-methoxyindol-3-ylmethyl glucosinolate. Significant differences $(P \leq 0.05)$ between means $( \pm \mathrm{SE})$ were determined by Tukey HSD tests in conjunction with a two-way ANOVA

substrates, sinigrin and 3MSOP-GSL, two shorter chain aliphatic substrates, supported the highest rate of activation (Fig. 2c). This observed catalytic preference was further confirmed by the enzyme kinetic parameters of BMY for selected substrates, with the shorter chain aliphatic glucosinolates 3MSOP-GSL and 4MSOB-GSL serving as the best substrates (Table 1). Denatured B. brassicae proteins and proteins of empty vector-transformed $E$. coli both failed to degrade any substrates, as expected (Supplementary file). 
(a)

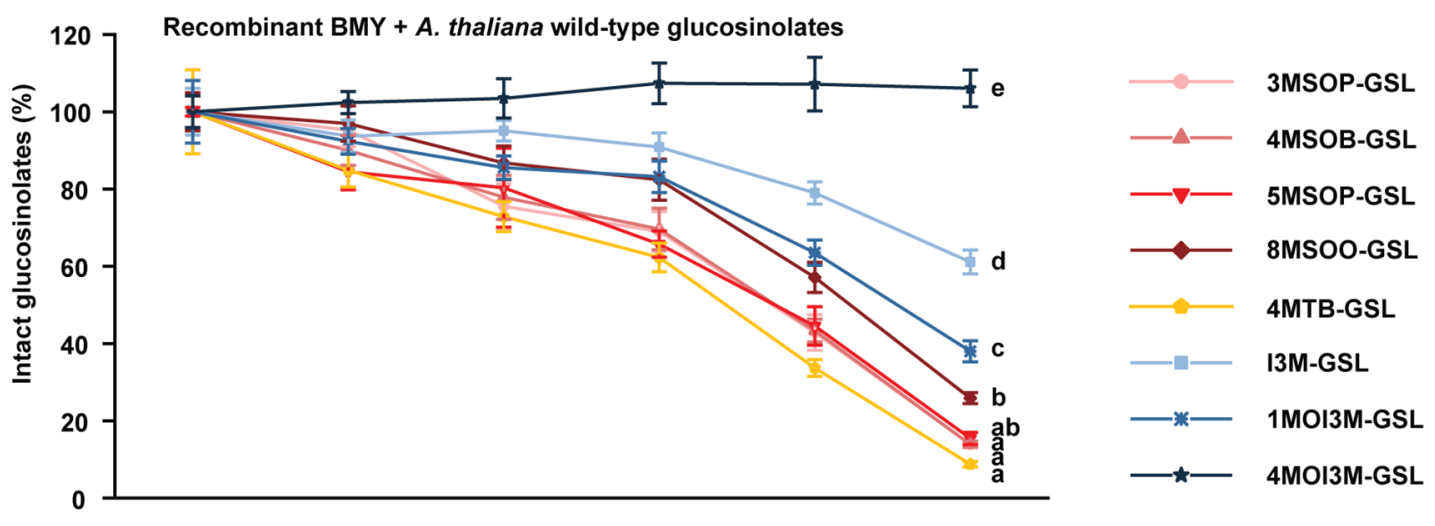

(b)

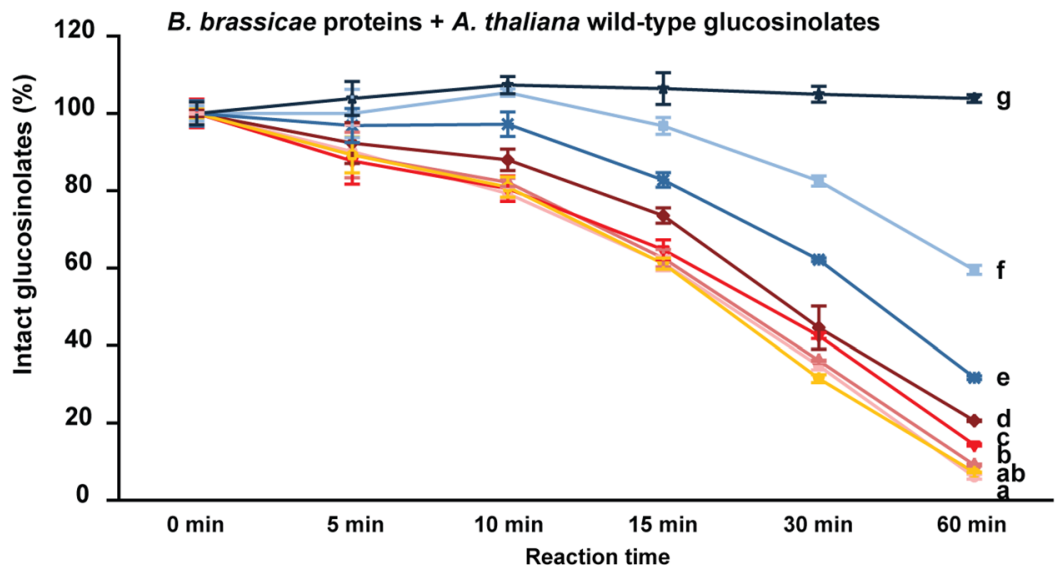

(c)

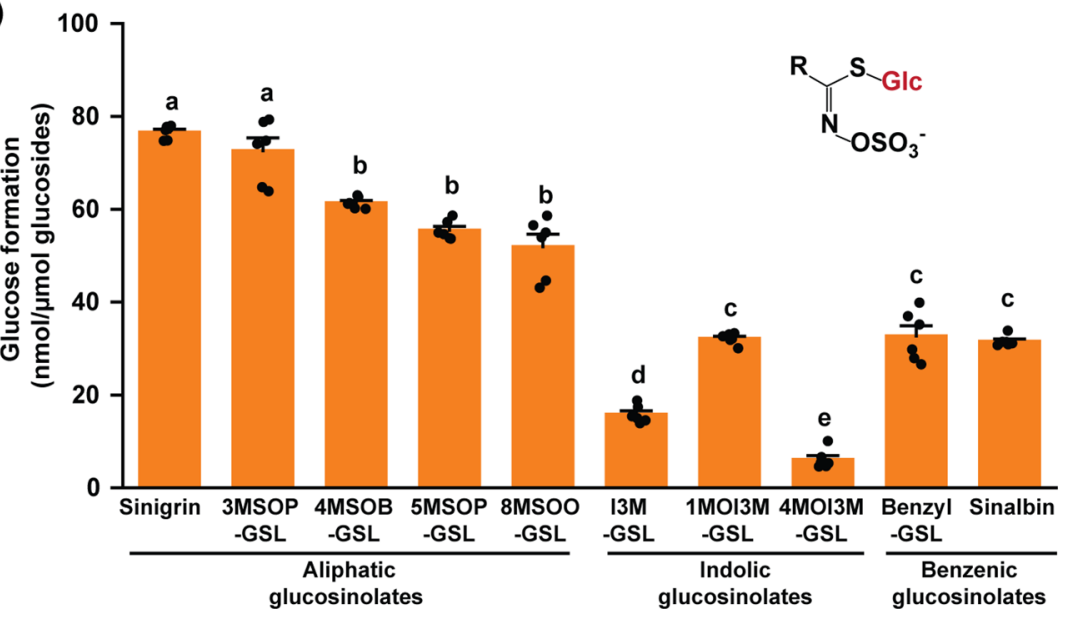

Fig. 2 The enzymatic activity of $B$. brassicae myrosinase (BMY) is biased toward aliphatic glucosinolates. Aliphatic glucosinolates were degraded much more quickly than indolic glucosinolates by purified recombinant BMY (a) and by a crude protein extract from $B$. brassicae (b). The protein extract was from B. brassicae thirdinstar nymphs fed on A. thaliana myb28myb29cyp79b2cyp79b3 (no glucosinolates) plants (B. brassicae protein: $F_{7,16}=3086, P \leq 0.001$; recombinant BMY: $F_{7,16}=192.2, P \leq 0.001 ; n=3$ in all points). c Quantification of glucose formed by BMY activation of selected glucosinolates from the three classes $\left(F_{9,50}=249.1, P \leq 0.001 ; n=6\right.$ in all bars). Sinigrin: 2-propenyl glucosinolate; 3MSOP-GSL, 3-methylsulfinylpropyl glucosinolate; 4MSOB-GSL, 4-methylsulfinylbutyl glucosinolate; 5MSOP-GSL, 5-methylsulfinylpentyl glucosinolate; 8MSOO-GSL, 8-methylsulfinyloctyl glucosinolate; 4MTB, 4-methylthiobutyl glucosinolate; I3M-GSL, indolyl-3-methyl glucosinolate; 1MOI3M-GSL, 1-methoxyindol-3-ylmethyl glucosinolate; 4MOI3MGSL, 4-methoxyindol-3-ylmethyl glucosinolate; benzyl-GSL: benzyl glucosinolate; sinalbin: $p$-hydroxybenzyl glucosinolate. Significant differences $(P \leq 0.05)$ between means $( \pm$ SE) were determined by Tukey HSD tests in conjunction with one-way ANOVA 
Table 1 Enzyme kinetic parameters of BMY toward different glucosinolates

\begin{tabular}{lllrr}
\hline Glucosinolates & \multicolumn{1}{l}{$\begin{array}{l}v_{\max } \\
\mu \mathrm{mol} \mathrm{mg} \mathrm{mg}^{-1} \mathrm{~min}^{-1}\end{array}$} & \multicolumn{1}{l}{$\begin{array}{l}K_{\mathrm{M}} \\
\mathrm{mM}\end{array}$} & \multicolumn{1}{c}{$\begin{array}{l}k_{\mathrm{cat}} \\
\mathrm{s}^{-1}\end{array}$} & \multicolumn{1}{c}{$\begin{array}{l}k_{\mathrm{cat}} / K_{\mathrm{M}} \\
\mathrm{mM}^{-1} \mathrm{~s}^{-1}\end{array}$} \\
\hline 3MSOP-GSL & $12.44 \pm 1.37$ & $0.44 \pm 0.12$ & $11.14 \pm 1.23$ & $25.58 \pm 2.82$ \\
4MSOB-GSL & $10.40 \pm 1.17$ & $0.59 \pm 0.14$ & $9.32 \pm 1.04$ & $15.79 \pm 1.77$ \\
5MSOP-GSL & $13.57 \pm 2.37$ & $0.72 \pm 0.26$ & $12.15 \pm 2.13$ & $16.78 \pm 2.94$ \\
8MSOO-GSL & $11.73 \pm 1.95$ & $0.75 \pm 0.25$ & $10.51 \pm 1.75$ & $13.93 \pm 2.32$ \\
1MOI3M-GSL & $5.06 \pm 0.55$ & $0.63 \pm 0.15$ & $4.53 \pm 0.49$ & $7.16 \pm 0.77$ \\
I3M-GSL & $2.75 \pm 0.53$ & $0.52 \pm 0.22$ & $2.46 \pm 0.47$ & $4.74 \pm 0.91$ \\
Benzyl-GSL & $8.78 \pm 3.00$ & $2.40 \pm 1.17$ & $7.86 \pm 2.69$ & $3.28 \pm 1.12$ \\
Sinalbin & $6.99 \pm 0.96$ & $1.33 \pm 0.31$ & $6.26 \pm 0.86$ & $4.71 \pm 0.65$ \\
\hline
\end{tabular}

The activity of affinity-purified recombinant BMY toward selected glucosinolates was measured with concentrations ranging from 1 to $1500 \mu \mathrm{M}\left(10 \mathrm{~min}\right.$ at $\left.28^{\circ} \mathrm{C}\right)$
Together, these results demonstrate that the catalytic activity of BMY is highest toward aliphatic glucosinolates, in particular those with shorter side chains.

\section{Glucosinolate metabolites found in B. brassicae after simulated predation}

The rupture of aphid tissues triggers the activation of sequestered glucosinolates, but the metabolites thereby formed have not been examined in detail, in spite of their important physiological implications. Therefore, we used a brush to gently stroke $B$. brassicae, mimicking an initial predator attack, and then analyzed the products resulting from hydrolysis of 4MSOB-GSL, the major aliphatic glucosinolate present in both $A$. thaliana wild-type Col-0 plants and aphids fed upon it (Fig. 1c). 4MSOB-GSL hydrolysis by the aphids led to both 4MSOB-ITC and the corresponding simple nitrile $4 \mathrm{MSOB}-\mathrm{CN}$ as primary products (Fig. 3a). A significant drop (25\%) in accumulated 4MSOB-GSL levels occurred during the 5 min after external mechanical stimulation, paired with a concomitant generation of three types of 4MSOB-metabolites, namely, 4MSOB-CN, 4MSOBITC, and 4MSOB-ITC-GSH (glutathione-ITC conjugate) (Fig. 3a,b). These three 4MSOB-metabolites were abundant, with the formation of 4MSOB-ITC (6.3-fold increase after external mechanical damage) being higher than the other two metabolites (2.1- and 3.5-fold increase for 4MSOB-CN and 4MSOB-ITC-GSH, respectively). Therefore, 4MSOBITC represents only a portion of 4MSOB-GSL metabolites produced upon a stimulus mimicking predation. Twenty minutes after mechanical damage, the concentrations of two downstream ITC-conjugates of the mercapturic acid pathway (4MSOB-ITC-CG (cysteinyl-glycine) and 4MSOB-ITC-Cys (cysteine)) were also elevated; the presumed final product of the mercapturic acid pathway, 4MSOB-ITC-NAC, was undetectable at all time points (Fig. 3b). We additionally quantified products of the activation of I3M-GSL, the major indolic glucosinolate accumulated in B. brassicae. In stark contrast to 4MSOB-GSL, the direct hydrolysis product (indole-3-acetonitrile) was too scarce for detection; instead, several likely non-toxic metabolites downstream of I3MITC, namely, I3C and I3M-ascorbate, were detected after I3M-GSL activation (Fig. S4). Overall, these results suggest that $B$. brassicae activates both classes of glucosinolates during an attack, with the aliphatic 4MSOB-GSL being converted into both the corresponding ITC and simple nitrile, and the hydrolysis products are partially converted to nontoxic conjugates.

In plants of the Brassicales order, the formation of 4MSOB-CN from 4MSOB-GSL is mediated by the presence of specifier proteins and the cofactor Fe (II) (Eisenschmidt-Bönn et al. 2019). To examine the factors affecting glucosinolate hydrolysis in $B$. brassicae aphids, we conducted in vitro enzyme assays using both a crude $B$. brassicae protein extract and purified BMY, and determined that formation of 4MSOB-CN was in apparent competition with the production of 4MSOB-ITC and relied on Fe (II) in a concentration-dependent manner, apparently without the need for an additional specifier protein (Fig. 3c). We further compared Fe (II) contents in B. brassicae and A. thaliana; the $\mathrm{Fe}$ (II) content in aphids exceeded that in the plant by about 30-fold, irrespective of whether the aphid had fed on plants containing or lacking aliphatic glucosinolates (Fig. 3d).

\section{Prey-derived aliphatic ITCs negatively affect growth and development of a lacewing predator}

We next asked how interfering with glucosinolate accumulation by the aphid would affect higher trophic levels. We focused on the generalist predatory lacewing $C$. carnea. To manipulate levels of glucosinolates in aphids, we fed them two genotypes of $A$. thaliana differing only in endogenous glucosinolate content: Col-0 wild-type plants with their natural glucosinolate content, and myb28myb29 plants without aliphatic glucosinolates. We then quantified the growth and development of $C$. carnea fed with aphids from either of 
(a)

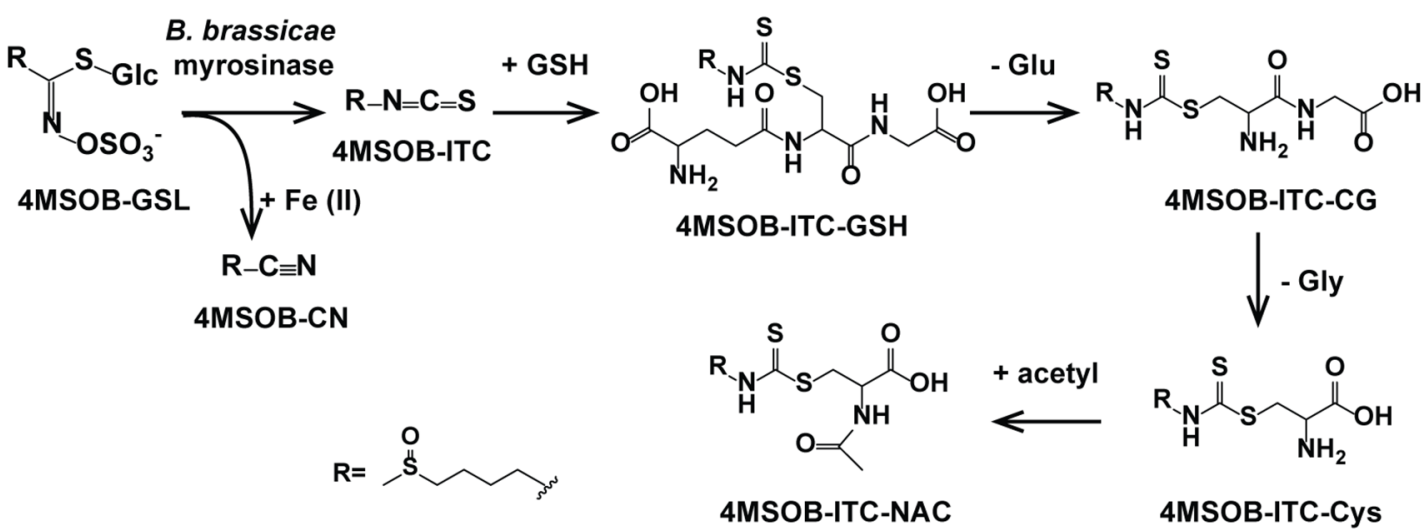

(b)

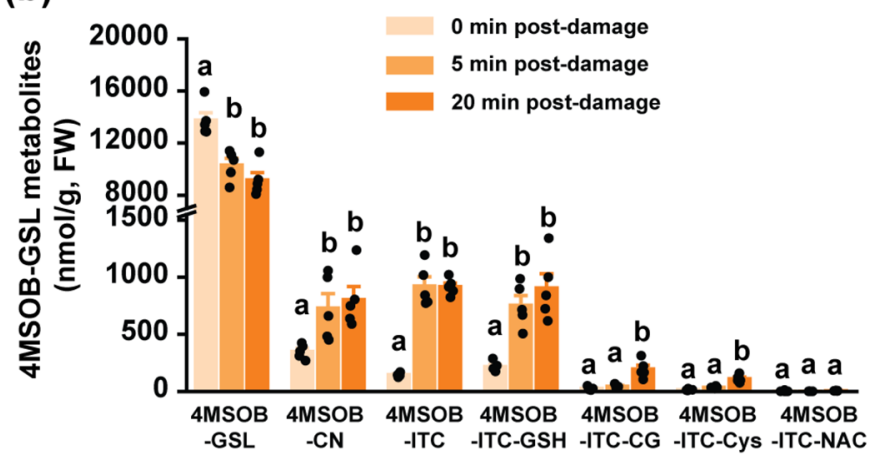

(d)

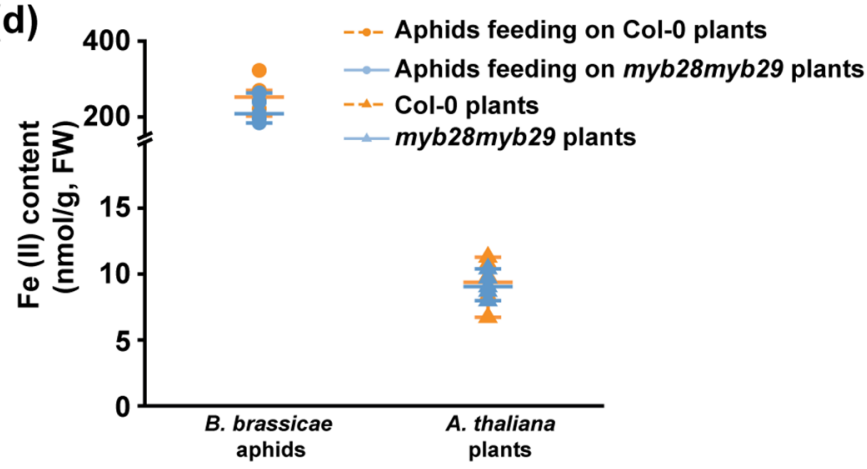

(c)

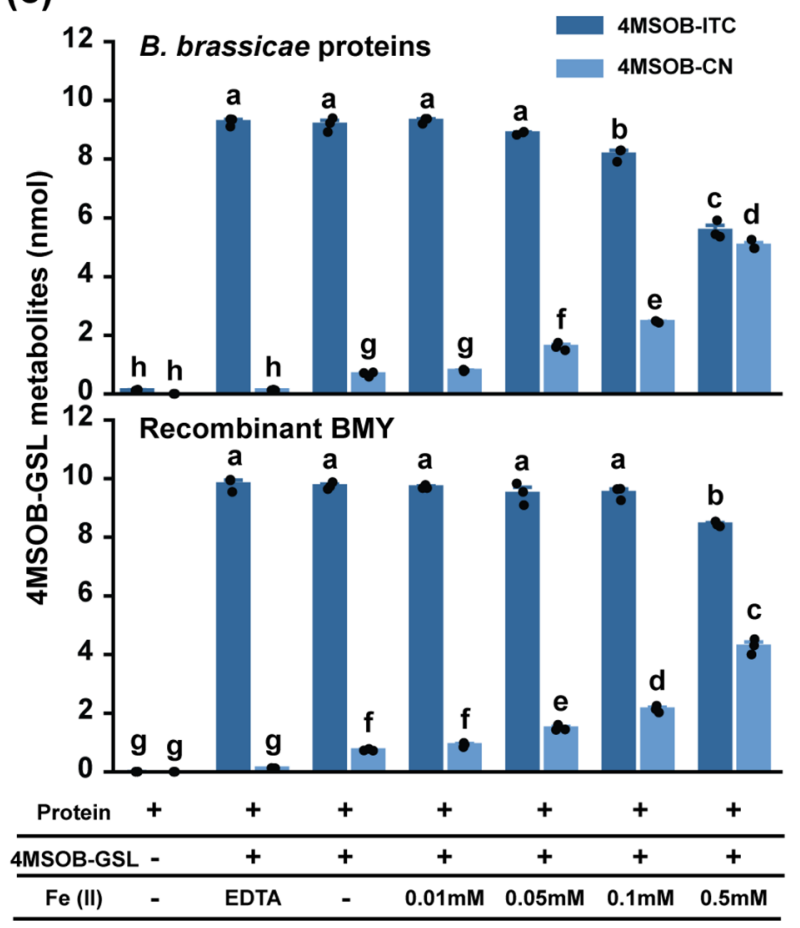

Fig. 3 4MSOB-GSL metabolism in $B$. brassicae after simulated predation. a An overview of the general pathways for 4MSOB-GSL hydrolysis and ITC conjugation. Note that the substrate 4MSOB-GSL is metabolized into two distinct pathways, forming either the nitrile or the ITC derivatives, respectively. b Quantification of 4MSOBGSL metabolites induced by simulated predation. Fourth-instar stage $B$. brassicae nymphs underwent a gentle simulated attack by brush stroking. $n=5$ in all bars. 4MSOB-GSL, $F_{2,12}=19.22, P \leq 0.001$; 4MSOB-CN, $F_{2,12}=5.891, P \leq 0.05 ;$ 4MSOB-ITC, $\quad F_{2,12}=78.22$, $P \leq 0.001 ; \quad 4 \mathrm{MSOB}-\mathrm{ITC}-\mathrm{GSH}, \quad F_{2,12}=16.71, \quad P \leq 0.001 ; \quad 4 \mathrm{MSOB}-$ ITC-CG, $F_{2,12}=20.07, P \leq 0.001$; 4MSOB-ITC-Cys, $F_{2,12}=33.16$, $P \leq 0.001$; 4MSOB-ITC-NAC, $F_{2,12}=2.395, P \geq 0.05$. c Conversion of $4 \mathrm{MSOB}-\mathrm{GSL}$ to $4 \mathrm{MSOB}-\mathrm{CN}$ requires the presence of Fe (II) and

those groups. A striking reduction in body weight occurred in lacewing larvae fed with wild-type-reared aphids relative to $m y b 28 m y b 29$-reared aphids; a statistical difference in
BMY. The extracted B. brassicae protein (treatments: $F_{6,28}=1077$, $P \leq 0.001$; metabolites: $F_{1,28}=16625, P \leq 0.001$; treatments $\times$ metabolites: $F_{6,28}=1079, P \leq 0.001 ; n=3$ in all bars) and recombinant BMY (treatments: $F_{6,28}=1052, P \leq 0.001$; metabolites: $F_{1,28}=18164$, $P \leq 0.001$; treatments $\times$ metabolites: $F_{6,28}=690.2, P \leq 0.001 ; n=3$ in all bars) were incubated with 4MSOB-GSL in the presence of other co-factors. 4MSOB-CN formation is positively correlated with the addition of $\left(\mathrm{NH}_{4}\right)_{2} \mathrm{Fe}\left(\mathrm{SO}_{4}\right)_{2}$ in the reaction system, but is blocked by adding the Fe (II) scavenger EDTA. d Fe (II) contents in fourth stage $B$. brassicae nymphs and in the aphid host plant. Significant differences $(P \leq 0.05)$ between means $( \pm$ s.e. $)$ were determined by Tukey HSD tests in conjunction with one-way ANOVA in $\mathbf{b}$, and two-way ANOVA in $\mathbf{c}$

predator weights emerged as early as 5 days post-hatching and became more dramatic during the rest of our experimental period (17 days post-hatching) (Fig. 4a). This pattern did 

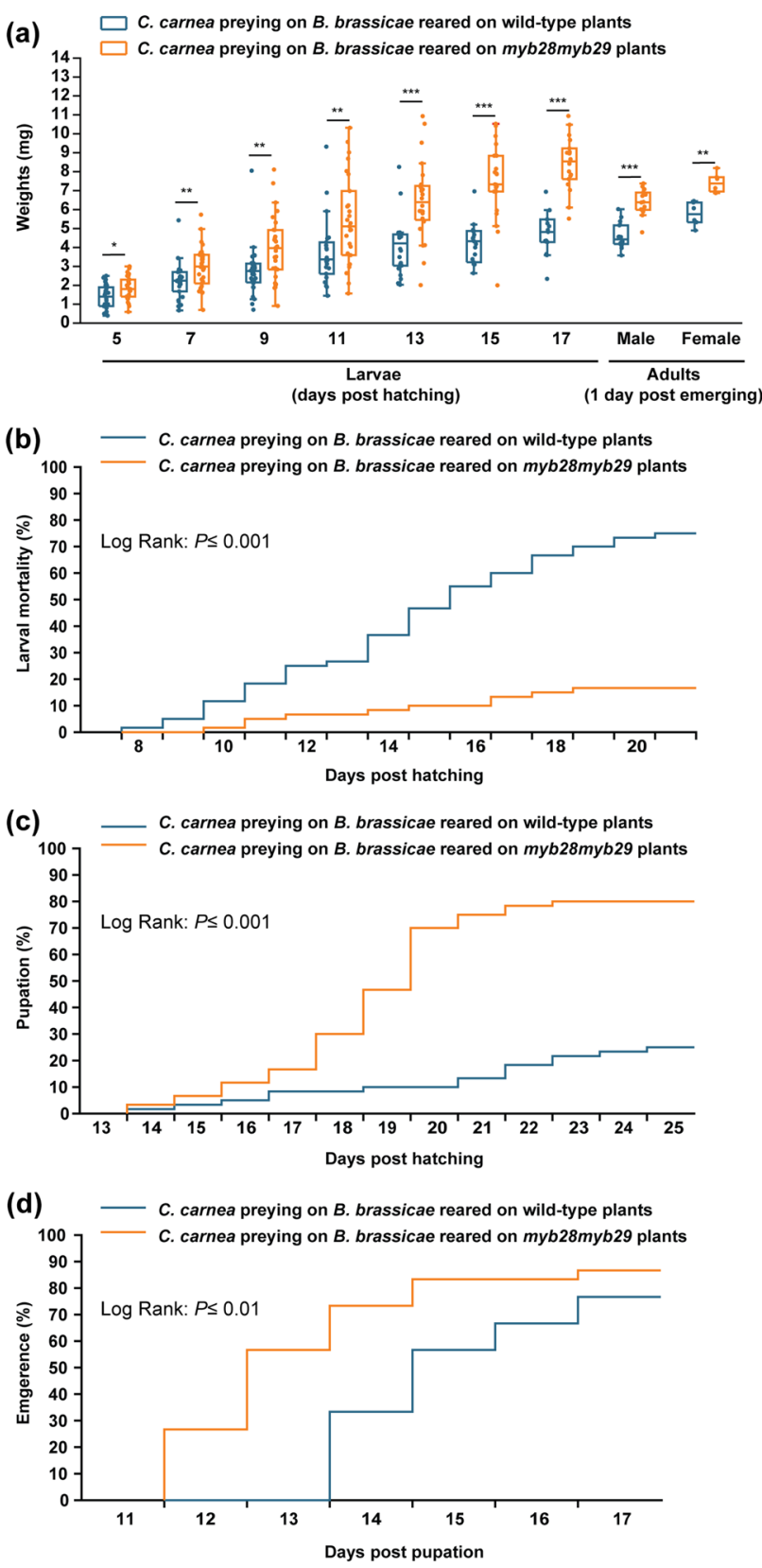

Fig. 4 Ingestion of glucosinolate-containing cabbage aphids severely reduces growth and survival of larvae of the predatory lacewing, $C$. carnea. a Weights of $C$. carnea larvae fed on B. brassicae that were reared on either wild-type A. thaliana Col-0 plants (wild-type glucosinolates) or myb28myb29 plants (no aliphatic glucosinolates) (5 day, $Z=2.536, P \leq 0.05, n=30$ for both; 7 day, $Z=2.868, P \leq 0.01, n=30$ for both; 9 day, $Z=2.964, P \leq 0.01, n=28$ and 30, respectively; 11 day, $Z=2.764, P \leq 0.01, n=23$ and 27 , respectively; 13 day, $Z=3.925, P \leq 0.001, n=22$ and 24 , respectively; 15 day, $Z=4.564$, $P \leq 0.001, n=19$ and 21 , respectively; 17 day, $Z=4.754, P \leq 0.001, n=15$ and 18 , respectively; male, $Z=4.112, P \leq 0.001, n=14$ for both; female, $Z=2.802$, $P \leq 0.01, n=6$ for both). b The larval mortality of $C$. carnea preying on aphids reared on either wild-type or myb28myb29 plants as food sources (Log Rank, $X^{2}=39.909, P \leq 0.001 ; n=60$ for all treatments). c Pupation rate of $C$. carnea larvae (Log Rank, $X^{2}=44.185, P \leq 0.001 ; n=60$ for all treatments) and d subsequent adult emergence rate after feeding on aphids reared on either wild-type or myb28myb29 plants (Log Rank, $X^{2}=8.965, P \leq 0.01 ; n=30$ for all treatments). Significant differences ( $P \leq 0.05$, two-tailed assay) between medians were determined by Mann-Whitney $U$ Test in a, and significant differences $(P \leq 0.05)$ were determined by Kaplan-Meier survival analyses in $\mathbf{b}-\mathbf{d}$. Asterisks represent: $* P \leq 0.05 ; * * P \leq 0.01 ; * * * P \leq 0.001$ not differ between male and female insects. The mortality of lacewing larvae reached approximately $70 \%$ after 20 days feeding on wild-type-reared aphids; however, only $15 \%$ of lacewings fed with myb28myb29-reared aphids died over the same time span (Fig. 4b). C. carnea larvae fed with wildtype-reared aphids also had much lower pupation success (less than 30\%) than counterparts fed with myb28myb29reared aphids (around 80\%) at the end of the experiment (25 days post-hatching) (Fig. 4c). Further, C. carnea fed with myb28myb29-reared aphids exhibited a shortened duration of the pupal stage, followed by a higher emergence success compared with lacewings fed with aphids reared on wild-type A. thaliana (Fig. 4d).

\section{Ingestion of high amounts of 4MSOB-ITC overwhelms the detoxification capability of $C$. carnea}

The severely impaired development of the predatory lacewing $C$. carnea exposed to ITCs (Fig. 4) suggested that its intrinsic detoxification capacity was insufficient against the high levels of ITCs ingested from its $B$. brassicae prey. To examine the efficiency of ITC detoxification in $C$. carnea, we provided $C$. carnea larvae with a constant diet of aphids fed on wild-type Col-0 A. thaliana starting from hatching. We then profiled the 4MSOB-metabolites in these lacewing larvae 15 days post-hatching (third-instar larval stage). Strikingly, large quantities of the non-toxic ITC metabolite 4MSOB-ITC-NAC were detected in both the larval anal secretion and its body (Fig. 5). While 4MSOB-ITC-NAC was itself absent in aphids (Fig. 3), the concentration of this metabolite in lacewing larvae was higher than other glucosinolate derivatives. The toxic 4MSOB-ITC was also abundant in the anal secretion, together with ITC-conjugates, while lower concentrations of 4MSOB-ITC remained in the lacewing larval body (Fig. 5). The simple nitrile 4MSOB-CN, another metabolite produced by $B$. brassicae, was present in high concentrations both in the anal secretion and larval bodies. Of note, the concentration of 4MSOB-CN was about twofold higher than 4MSOB-ITC in lacewing larval bodies, in stark contrast to aphids (Fig. 3). In pupae and adult lacewings, significantly lower concentrations of 4MSOBmetabolites were detected, except only for 4MSOB-ITCNAC in the meconium, eventually resulting in adults free from 4MSOB-metabolites (Fig. 5). In all, these results show that $C$. carnea larvae expend a large amount of energy dealing metabolically with the high concentrations of toxic 4MSOB-ITC ingested, leading to stark negative effects on their growth and survival. Nevertheless, surviving insects can excrete both 4MSOB-ITC and its derivatives, in spite of their metabolism being insufficient to deactivate all of the ingested toxin. 


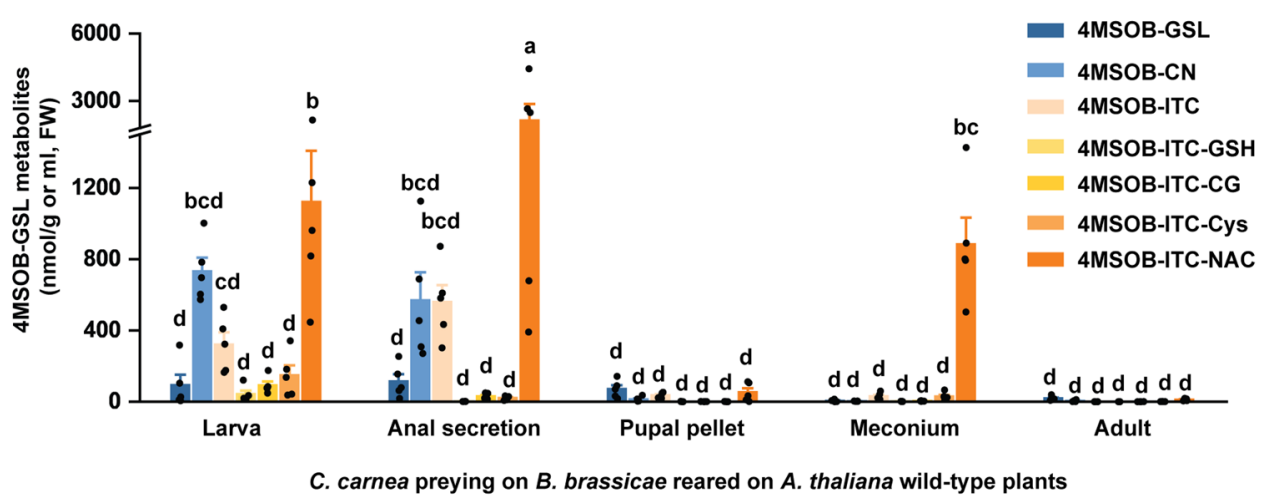

Fig. 5 C. carnea alleviates the toxicity of the 4MSOB-ITC from ingested aphids by conjugation and mobilization. Detoxification of ingested 4MSOB-ITC includes metabolism into the detoxified product 4MSOB-ITC-NAC via the general mercapturic acid pathway and mobilization into the anal secretion. The remaining 4MSOB-

\section{Discussion}

The cabbage aphid is a destructive agricultural pest that specializes on plants of the order Brassicales, including crops such as cabbages and mustards. Although Brassicales species produce a wide variety of glucosinolates, our results clearly show that the cabbage aphid accumulates predominantly aliphatic glucosinolates (Fig. 1), in line with other studies (Kos et al. 2011). Moreover, the accumulation of aliphatic glucosinolates occurs at different rates, dependent on the side chain structure (Fig. 1b). Although the mechanism dictating the selective sequestration of particular glucosinolates is not understood, it likely involves specific transporters such as the $\mathrm{ABC}$ transporters that allow translocation of plant-derived materials across cellular membranes (Petschenka and Agrawal 2016; Strauss et al. 2013).

Sequestration of plant defense compounds is more typical for specialist than generalist herbivores (Beran et al. 2014; Bramer et al. 2017; Kazana et al. 2007; Müller et al. 2001). It is one of a range of adaptations of Brassicales-feeding herbivores to facilitate the colonization of glucosinolatecontaining host plants (Cao et al. 2018; Cole 1997; Louis et al. 2012). Sequestration may remove intact glucosinolates from the gut before they can become activated by the plant myrosinases (Abdalsamee et al. 2014), which can resist digestion and might act in the insect gut lumen (Vassão et al. 2018). When later activated by the insect, these same glucosinolates can serve as defenses against predators and parasitoids (Chaplin-Kramer et al. 2011; Kos et al. 2011). The selectivity of glucosinolate sequestration in the cabbage aphid may result from a preference for compounds that are more effective in defense. Selectivity, such as the preference against indolic glucosinolates, could also help reduce the risk of autotoxicity. In that regard, certain indolic glucosinolates and their derivatives have been shown to cause
ITC-NAC is excreted in the meconium after adult emergence. Significant differences (tissues: $F_{4,140}=15.99, P \leq 0.001$; metabolites: $F_{6,140}=21.82, P \leq 0.001$; tissue $\times$ metabolites: $F_{24,140}=5.295$, $P \leq 0.001 ; n=5$ in all bars) between means ( \pm s.e.) were determined by Tukey HSD test in conjunction with a two-way ANOVA

negative effects on the performance and physiology of some aphids (Kim and Jander 2007; Kim et al. 2008). Aphids might also break down indolic glucosinolates during feeding to limit their uptake (Fig. 1) (Kos et al. 2011).

The endogenous cabbage aphid myrosinase (BMY) enables the cabbage aphid to produce defensive ITCs from the sequestered glucosinolates (Jones et al. 2002; Kazana et al. 2007) as long as the enzyme is able to accept the sequestered glucosinolates as substrates. We report here for the first time that the preference of BMY toward different glucosinolate substrates in vitro corresponds well to the pattern of glucosinolates sequestered by the aphid in vivo (Figs. 1 and 2). Aliphatic glucosinolates may be preferred as substrates because of more favorable interactions with enzymatic binding sites (Husebye et al. 2005). Preference for shorter chain aliphatic glucosinolates may be due to the specific active site architecture and could have been selected for since shorter chain ITCs have greater volatility than longer chain ITCs and thus serve as better signals in aphid colonies to warn of predation. The hydrolysis products of some shorter chain aliphatic glucosinolates enhance neuronal response to the alarm pheromone of aphids (Dawson et al. 1987; Kazana et al. 2007) and impair the performance and physiology of aphid predators (Kos et al. 2011). The weak activity of BMY with indolic glucosinolates corresponds to their low accumulation level. BMY is completely inactive with the substrate $4 \mathrm{MOI} 3 \mathrm{M}$, and this glucosinolate is barely detected in the body of cabbage aphid (Fig. 1).

In addition to ITCs, our results reveal that the cabbage aphid produces substantial amounts of nitriles as well as ITC-conjugates upon glucosinolate activation (Fig. 3). In the presence of BMY, the diversion of aliphatic glucosinolates into nitriles requires $\mathrm{Fe}$ (II) in a concentration-dependent manner (Fig. 3), possibly in tandem with a nitrile-specifier protein (NSP) as in plants (Wittstock et al. 2016). The simple 
nitriles formed are known to be less toxic than ITCs, but benefit plants by attracting parasitoids or deterring herbivore oviposition (Mumm et al. 2008). They may also have roles as defensive signals for aphids, but further research is needed. If nitriles do function in defense, the cabbage aphid's use of both $\mathrm{Fe}$ (II) and BMY in glucosinolate hydrolysis might help adjust the balance of glucosinolate metabolites.

The widespread application of toxic chemicals for the management of pest herbivores can have strong negative effects on nontargeted organisms, including pollinators. Hence, the application of natural enemies is increasingly considered as a more environmentally friendly part of integrated pest management strategies. However, how plantproduced defensive metabolites might affect the multiple trophic levels involved in such applications is often not well understood. It has been shown in some cases that such compounds can move up the food chain and affect not only the consuming pest herbivores, but subsequently also herbivore natural enemies (Gauld et al. 1992; Hartmann 2004; Harvey et al. 2003; Petschenka and Agrawal 2016), with potential unintended effects for plant protection. In Brassicales plants more specifically, plant-produced glucosinolates have been shown to influence predators (Sporer et al. 2020; Sun et al. 2019) and parasitoids (Sun et al. 2020) of herbivores. Cabbage aphid predators, such as $C$. carnea, can suffer significantly from ingesting insects containing glucosinolates. While $C$. carnea possesses a metabolic mechanism to detoxify ITCs via conjugation (Sun et al. 2019), this detoxification capacity appears to be limited. Although the performance and fitness of $C$. carnea larvae were not negatively affected by the low levels of 4MSOB-ITC present in sulfatase-deficient Plutella xylostella (Sun et al. 2019), they were significantly decreased by the much larger quantities of 4MSOB-ITC produced by the cabbage aphid (Figs. 4 and 5). These findings suggest that generalist predators like the lacewing might possess only a limited capacity to overcome the toxicity of prey defenses, although certain specialist predators might display stronger tolerance (Pratt et al. 2008). Research on a larger variety of cabbage aphid predators should give us a better picture of the effectiveness and roles of glucosinolate detoxification in herbivore natural enemy interactions. Here, we determined that $C$. carnea was strongly negatively affected by the aliphatic glucosinolates accumulated by $B$. brassicae aphids, highlighting the importance of these compounds in food chains. As such, this lacewing might be more suitable for cabbage aphid control on crops with low amounts of aliphatic glucosinolates, even if benzenic and indolic glucosinolates are abundant, than on varieties containing high concentrations of short-chain aliphatic glucosinolates.

\section{Author contributions}

RS, XJ, and DGV conceived and designed the research. RS and $\mathrm{XJ}$ conducted the experiments and analyzed the data. $\mathrm{RS}, \mathrm{XJ}$, and DGV wrote the paper. RS, DGV, and MR developed the analytical methods. All authors read, edited, and approved the manuscript.

Acknowledgements We thank Dr. Rieta Gols (Wageningen University \& Research, Wageningen, Netherlands) for generously providing B. brassicae colonies, as well as Katrin Luck and Bettina Raguschke (MPI-CE) for technical assistance.

Funding Open Access funding enabled and organized by Projekt DEAL. This study was supported by the China Scholarship Council (Grant number 201508330285), the Deutsche Forschungsgemeinschaft (DFG Collaborative Research Center 1127 ChemBioSys), and the Max Planck Society. The funders had no role in study design, data collection and analysis, decision to publish, or preparation of the manuscript.

Availability of data and materials Supplementary figures and tables are available in the Supplementary Information document. Files containing full result data and statistical analyses are available in the Supplementary data file.

\section{Compliance with ethical standards}

Conflict of interest The authors declare that they have no conflict of interest.

Ethical approval This article does not describe any studies that involve human participants. All applicable international, national, and/or institutional guidelines for the care and use of animals were followed.

Open Access This article is licensed under a Creative Commons Attribution 4.0 International License, which permits use, sharing, adaptation, distribution and reproduction in any medium or format, as long as you give appropriate credit to the original author(s) and the source, provide a link to the Creative Commons licence, and indicate if changes were made. The images or other third party material in this article are included in the article's Creative Commons licence, unless indicated otherwise in a credit line to the material. If material is not included in the article's Creative Commons licence and your intended use is not permitted by statutory regulation or exceeds the permitted use, you will need to obtain permission directly from the copyright holder. To view a copy of this licence, visit http://creativecommons.org/licenses/by/4.0/.

\section{References}

Abdalsamee MK, Giampà M, Niehaus K, Müller C (2014) Rapid incorporation of glucosinolates as a strategy used by a herbivore to prevent activation by myrosinases. Insect Biochem Mol Biol 52:115-123

Agerbirk N, Olsen CE (2012) Glucosinolate structures in evolution. Phytochemistry 77:16-45

Andréasson E, Jørgensen LB (2003) Localization of plant myrosinases and glucosinolates. In: Romeo JT (ed) Recent Advances in Phytochemistry, vol 37. Elsevier, Amsterdam, pp 79-99 
Beran F, Pauchet Y, Kunert G, Reichelt M, Wielsch N, Vogel H, Reinecke A, Svatoš A, Mewis I, Schmid D, Ramasamy S, Ulrichs C, Hansson BS, Gershenzon J, Heckel DG (2014) Phyllotreta striolata flea beetles use host plant defense compounds to create their own glucosinolate-myrosinase system. Proc Natl Acad Sci USA 111(20):7349-7354

Blažević I, Montaut S, Burčul F, Olsen CE, Burow M, Rollin P, Agerbirk N (2020) Glucosinolate structural diversity, identification, chemical synthesis and metabolism in plants. Phytochemistry 169:112100

Bramer C, Friedrich F, Dobler S (2017) Defence by plant toxins in milkweed bugs (Heteroptera: Lygaeinae) through the evolution of a sophisticated storage compartment. Syst Entomol 42(1):15-30

Brown KK, Hampton MB (2011) Biological targets of isothiocyanates. Biochim Biophys Acta 1810(9):888-894

Burow M, Müller R, Gershenzon J, Wittstock U (2006) Altered glucosinolate hydrolysis in genetically engineered Arabidopsis thaliana and its influence on the larval development of Spodoptera littoralis. J Chem Ecol 32(11):2333-2349

Cao HH, Zhang ZF, Wang XF, Liu TX (2018) Nutrition versus defense: why Myzus persicae (green peach aphid) prefers and performs better on young leaves of cabbage. PLoS ONE 13(4):e0196219

Chaplin-Kramer R, Kliebenstein DJ, Chiem A, Morrill E, Mills NJ, Kremen C (2011) Chemically mediated tritrophic interactions: opposing effects of glucosinolates on a specialist herbivore and its predators. J Appl Ecol 48(4):880-887

Cole RA (1997) The relative importance of glucosinolates and amino acids to the development of two aphid pests Brevicoryne brassicae and Myzus persicae on wild and cultivated brassica species. Entomol Exp Appl 85(2):121-133

Dawson GW, Griffiths DC, Pickett JA, Wadhams LJ, Woodcock CM (1987) Plant-derived synergists of alarm pheromone from turnip aphid, Lipaphis (Hyadaphis) erysimi (Homoptera, Aphididae). J Chem Ecol 13(7):1663-1671

Eisenschmidt-Bönn D, Schneegans N, Backenköhler A, Wittstock U, Brandt W (2019) Structural diversification during glucosinolate breakdown: mechanisms of thiocyanate, epithionitrile and simple nitrile formation. Plant J 99(2):329-343

Gabrys B (2008) Cabbage Aphid, Brevicoryne brassicae (L.) (Hemiptera: Aphididae). In: Capinera J.L. (ed) Encyclopedia of entomology. Springer, Dordrecht. https://doi. org/10.1007/978-1-4020-6359-6_440

Gauld ID, Gaston KJ, Janzen DH (1992) Plant allelochemicals, tritrophic interactions and the anomalous diversity of tropical parasitoids: the "nasty" host hypothesis. Oikos 65(2):353-357

Hanschen FS, Brüggemann N, Brodehl A, Mewis I, Schreiner M, Rohn S, Kroh LW (2012) Characterization of products from the reaction of glucosinolate-derived isothiocyanates with cysteine and lysine derivatives formed in either model systems or broccoli sprouts. J Agric Food Chem 60(31):7735-7745

Hartmann T (2004) Plant-derived secondary metabolites as defensive chemicals in herbivorous insects: a case study in chemical ecology. Planta 219(1):1-4

Harvey JA, Van Dam NM, Gols R (2003) Interactions over four trophic levels: foodplant quality affects development of a hyperparasitoid as mediated through a herbivore and its primary parasitoid. J Anim Ecol 72(3):520-531

Husebye H, Arzt S, Burmeister WP, Härtel FV, Brandt A, Rossiter JT, Bones AM (2005) Crystal structure at $1.1 \AA$ A resolution of an insect myrosinase from Brevicoryne brassicae shows its close relationship to $\beta$-glucosidases. Insect Biochem Mol Biol 35(12):1311-1320

Jeschke V, Gershenzon J, Vassão DG (2016) Insect detoxification of glucosinolates and their hydrolysis products. In: Stanislav K (ed) Advances in botanical research, vol 80. Academic Press, Cambridge, pp 199-245
Jones AME, Winge P, Bones AM, Cole R, Rossiter JT (2002) Characterization and evolution of a myrosinase from the cabbage aphid Brevicoryne brassicae. Insect Biochem Mol Biol 32(3):275-284

Kazana E, Pope TW, Tibbles L, Bridges M, Pickett JA, Bones AM, Powell G, Rossiter JT (2007) The cabbage aphid: a walking mustard oil bomb. Proc Royal Soc B: Biol Sci 274(1623):2271-2277

Kessing J, Mau R (1991) Cabbage Aphid, Brevicoryne Brassicae (Linnaeus). Department of Entomology: Honolulu, HI, USA, http://entne mdept.ufl.edu/creatures/veg/aphid/cabbage_aphid.htm

Kim JH, Jander G (2007) Myzus persicae (green peach aphid) feeding on Arabidopsis induces the formation of a deterrent indole glucosinolate. Plant J 49(6):1008-1019

Kim JH, Lee BW, Schroeder FC, Jander G (2008) Identification of indole glucosinolate breakdown products with antifeedant effects on Myzus persicae (green peach aphid). Plant J 54(6):1015-1026

Koroleva OA, Cramer R (2011) Single-cell proteomic analysis of glucosinolate-rich S-cells in Arabidopsis thaliana. Methods 54(4):413-423

Kos M, Kabouw P, Noordam R, Hendriks K, Vet LEM, Van Loon JJA, Dicke M (2011) Prey-mediated effects of glucosinolates on aphid predators. Ecol Entomol 36(3):377-388

Louis J, Singh V, Shah J (2012) Arabidopsis thaliana-Aphid Interaction. The Arabidopsis Book. The American Society of Plant Biologists, Rockville

Mikkelsen MD, Petersen BL, Glawischnig E, Jensen AB, Andreasson E, Halkier BA (2003) Modulation of CYP79 genes and glucosinolate profiles in Arabidopsis by defense signaling pathways. Plant Physiol 131(1):298-308

Mpumi N, Machunda RS, Mtei KM, Ndakidemi PA (2020) Selected insect pests of economic importance to Brassica oleracea, their control strategies and the potential threat to environmental pollution in Africa. Sustainability 12(9):3824

Müller C, Agerbirk N, Olsen CE, Boevé J-L, Schaffner U, Brakefield PM (2001) Sequestration of host plant glucosinolates in the defensive hemolymph of the sawfly Athalia rosae. J Chem Ecol 27(12):2505-2516

Mumm R, Burow M, Bukovinszkine'Kiss G, Kazantzidou E, Wittstock U, Dicke M, Gershenzon J (2008) Formation of simple nitriles upon glucosinolate hydrolysis affects direct and indirect defense against the specialist herbivore, Pieris rapae. J Chem Ecol 34(10):1311

Petschenka G, Agrawal AA (2016) How herbivores coopt plant defenses: natural selection, specialization, and sequestration. Curr Opinion Insect Sci 14:17-24

Pratt C, Pope TW, Powell G, Rossiter JT (2008) Accumulation of glucosinolates by the cabbage aphid Brevicoryne brassicae as a defense against two coccinellid species. J Chem Ecol 34(3):323-329

Rask L, Andréasson E, Ekbom B, Eriksson S, Pontoppidan B, Meijer J (2000) Myrosinase: gene family evolution and herbivore defense in Brassicaceae. Plant Mol Biol 42(1):93-114

Sønderby IE, Hansen BG, Bjarnholt N, Ticconi C, Halkier BA, Kliebenstein DJ (2007) A systems biology approach identifies a R2R3 MYB gene subfamily with distinct and overlapping functions in regulation of aliphatic glucosinolates. PLoS ONE 2(12):e1322-e1322

Sporer T, Körnig J, Beran F (2020) Ontogenetic differences in the chemical defence of flea beetles influence their predation risk. Funct Ecol 34(7):1370-1379

Strauss AS, Peters S, Boland W, Burse A (2013) ABC transporter functions as a pacemaker for sequestration of plant glucosides in leaf beetles. eLife 2:e01096-e01096

Sun R, Gols R, Harvey JA, Reichelt M, Gershenzon J, Pandit SS, Vassão DG (2020) Detoxification of plant defensive glucosinolates by an herbivorous caterpillar is beneficial to its endoparasitic wasp. Mol Ecol 29(20):4014-4031

Sun R, Jiang X, Reichelt M, Gershenzon J, Pandit SS, Vassão DG (2019) Tritrophic metabolism of plant chemical defenses and its effects on herbivore and predator performance. eLife 8:e51029 
Vassão DG, Wielsch N, Gomes AMMM, Gebauer-Jung S, Hupfer Y, Svatoš A, Gershenzon J (2018) Plant defensive $\beta$-glucosidases resist digestion and sustain activity in the gut of a lepidopteran herbivore. Frontiers Plant Sci 9:1389

Wittstock U, Gershenzon J (2002) Constitutive plant toxins and their role in defense against herbivores and pathogens. Curr Opin Plant Biol 5(4):300-307

Wittstock U, Meier K, Dörr F, Ravindran BM (2016) NSP-dependent simple nitrile formation dominates upon breakdown of major aliphatic glucosinolates in roots, seeds, and seedlings of Arabidopsis thaliana Columbia-0. Frontiers Plant Sci 7:1821

Publisher's Note Springer Nature remains neutral with regard to jurisdictional claims in published maps and institutional affiliations. 